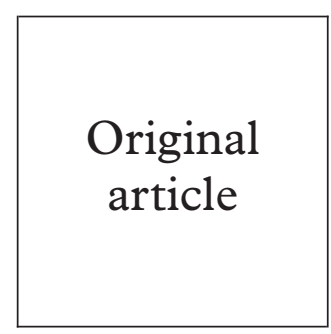

\section{Knowledge of Chlamydia trachomatis genital infection and its consequences in people attending a genitourinary medicine clinic}

\author{
Penny Devonshire, Richard Hillman, Simon Capewell, Brian J Clark
}

Objectives: To assess knowledge of Chlamydia trachomatis infections, with a comparison of knowledge of Neisseria gonorrhoeae infections.

Methods: A cross sectional survey, by self completed questionnaire, of 200 subjects attending a genitourinary outpatient clinic.

Results: The response rate was $82 \%$ (90 male and 73 female). $51 \%$ of men ( $60 \%$ of females) had heard of chlamydia. $65(82 \%)$ were unaware of the potential consequences of infection. $66 \%$ were unaware that the disease could be asymptomatic. Significantly more men $(77 \%)$ than women $(60 \%)$ had heard of gonorrhoea. Most participants $(68 \%-82 \%)$ knew little of the possible consequences of this infection, and only $26 \%$ were aware that it could be asymptomatic. Knowledge was higher regarding fertility topics. There was no correlation between knowledge and either age or socioeconomic status. However, greater knowledge was displayed by those who read health information leaflets always or often. For both men and women, the preferred source of health information was the doctor. Other popular sources were health information leaflets, women's magazines, and television.

Conclusions: Barely half the participants had heard of chlamydia and gonorrhoea. Further knowledge of either infection was very poor. There are serious implications for public health. The reasons for this are unclear and require exploration before targeted health promotion. Doctors and the popular media are acceptable, and potentially effective, sources of information. Acquisition of knowledge is important, both to reduce sexual risk taking behaviour and its consequences, and to allow for informed consent for chlamydia screening programmes.

(Sex Transm Inf 1999;75:409-411)

Keywords: genitourinary medicine; Chlamydia trachomatis; information sources

\section{Introduction}

Sexually transmitted diseases remain of major importance throughout the world and the United Kingdom. ${ }^{12}$ Non-gonococcal urethritis is now the commonest acute sexually transmitted disease in industrialised countries. About half of cases are caused by Chlamydia trachomatis, ${ }^{3-6}$ also the commonest cause of pelvic inflammatory disease, infertility, and ectopic pregnancies. Some men and most women with $C$ trachomatis genital tract infections are asymptomatic ${ }^{4}$ and carriage may persist for months. ${ }^{7}$ The associated economic and human suffering costs are high. ${ }^{8}$

Chlamydial genital infections fulfil many criteria for screening and pilot schemes for national screening programmes have been proposed. $^{9} 10$

Although incidence might be decreased by prevention of infection, the public requires knowledge of symptoms and sequelae to develop effective health promotion initiatives. Studies elsewhere suggest low levels of knowledge. ${ }^{11-13}$ This study aimed to determine the proportion of genitourinary medicine clinic attendees who were aware of $C$ trachomatis and the consequences of infection, contrasting this with knowledge of Neisseria gonorrhoea.

Dr B Clark, Insto:

Ophthalmology, University

College London, Bath Street,

London

Accepted for publication 22 September 1999

\section{Subjects and methods}

Consecutive attendees (100 of each sex) to a genitourinary medicine outpatient clinic were invited to complete a short anonymous questionnaire covering (1) patient demographics; (2) knowledge about gonorrhoea, chlamydia, and fertility; and (3) actual and preferred sources of health information. (A copy of the questionnaire can be obtained from the journal office.)

Patients' knowledge of gonorrhoea, chlamydia, and matters relating to fertility was scored as one point for a correct answer, none for "don't know," and minus one point for a wrong answer. These marks were summed to create combined scores for "gonorrhoea knowledge," "chlamydia knowledge," "infertility knowledge," and "total knowledge." Socioeconomic status was based on the Carstairs deprivation scores. ${ }^{14}$

Data were analysed by appropriate statistical methods $^{15}\left(\chi^{2}\right.$, Mann-Whitney $U$ test, Wilcoxon matched pairs signed rank sum test, Pearson correlation coefficients, KruskalWallis test) in a statistical package (Minitab for Windows).

\section{Results}

Of the 200 subjects, $163(82 \%)$ completed questionnaires; 90 participants were male $(55 \%)$ and 73 were female (45\%). Their median age was 26 (interquartile range 22-33), with $10(6 \%)$ teenagers (three males, seven females). The median Carstairs deprivation score was 5.3 (interquartile range 3.5-6.3). 
Table 1 Comparison between the sexes on their knowledge of gonorrhoea and chlamydia complications

\begin{tabular}{|c|c|c|c|c|c|c|c|}
\hline \multirow[b]{3}{*}{$\begin{array}{l}\text { Does infection cause this } \\
\text { complication? }\end{array}$} & \multirow[b]{3}{*}{ Sex } & \multicolumn{6}{|c|}{ Response of subjects (\%) } \\
\hline & & \multicolumn{3}{|c|}{ Gonorrhoea } & \multicolumn{3}{|c|}{ Chlamydia } \\
\hline & & Yes & No & $\begin{array}{l}\text { Don't } \\
\text { know }\end{array}$ & Yes & No & $\begin{array}{l}\text { Don't } \\
\text { know }\end{array}$ \\
\hline \multirow[t]{2}{*}{ Heart disease } & males & 0 & 18.9 & 81.1 & 0 & 24.4 & 75.6 \\
\hline & females & 2.7 & 16.4 & 80.8 & 1.4 & 17.8 & 80.8 \\
\hline \multirow{2}{*}{ Diarrhoea } & males & 4.4 & 16.7 & 78.9 & 0 & 18.9 & 81.1 \\
\hline & females & 8.2 & 9.6 & 82.2 & 2.7 & 13.7 & 83.6 \\
\hline \multirow{2}{*}{ Infertility ${ }^{\star}$} & males & 22.2 & 7.8 & 70 & 35.6 & 4.4 & 70 \\
\hline & females & 31.5 & 1.4 & 67.1 & 39.7 & 0 & 60.3 \\
\hline \multirow[t]{2}{*}{ Eye infection } & males & 7.8 & 14.4 & 77.9 & 2.2 & 20 & 77.8 \\
\hline & females & 9.6 & 12.3 & 78.1 & 6.9 & 19.2 & 73.9 \\
\hline \multirow[t]{2}{*}{ Chest infection in babies } & males & 2.2 & 12.2 & 85.6 & 1.1 & 14.4 & 84.4 \\
\hline & females & 8.2 & 13.7 & 78.1 & 6.9 & 13.7 & 79.5 \\
\hline \multirow{2}{*}{ Lower tummy pains ${ }^{\star \star}$} & males & 12.2 & 7.8 & 80 & 10 & 8.9 & 81.1 \\
\hline & females & 21.9 & 4.1 & 73.9 & 30.1 & 2.7 & 67.1 \\
\hline \multirow[t]{2}{*}{ Genital discharge ${ }^{\star \star}$} & males & 50 & 2.2 & 47.8 & 23.3 & 7.8 & 68.9 \\
\hline & females & 41.1 & 1.4 & 57.5 & 38.4 & 0 & 61.6 \\
\hline \multirow[t]{2}{*}{ No symptoms in some people } & males & 18.9 & 7.9 & 73.3 & 16.7 & 7.9 & 75.6 \\
\hline & females & 23.3 & 1.4 & 75.3 & 21.9 & 4.1 & 73.9 \\
\hline
\end{tabular}

Male versus female: ${ }^{\star} \mathrm{p}=0.04,{ }^{\star \star} \mathrm{p}<0.01$.

Males and females were not significantly different. One third of the participants (52/ $163,32 \%)$ had children: 26 of the men $(29 \%)$ and 26 of the women (36\%). Of the women, 38 $(52 \%)$ had never been pregnant; only three $(1.8 \%)$ admitted to ever having treatment for infertility.

PATIENT KNOWLEDGE OF GONORRHOEA

Sixty nine of $90(77 \%)$ males had heard of gonorrhoea, significantly more than $44 / 73$ $(60 \%)$ females $(\mathrm{p}=0.02)$.

Only $48 \%$ were aware that genital discharge was a symptom. For the remaining seven questions, the majority (68-82\%) did not know that gonorrhoea caused these complications. A misconception existed that gonorrhoea did not cause eye infections. There was no significant difference between the sexes in their knowledge of gonorrhoea (table 1).

PATIENT KNOWLEDGE OF CHLAMYDIA

Forty six of $90(51 \%)$ males and $44 / 73(60 \%)$ females had heard of chlamydia $(\mathrm{p}=0.24)$.

For all eight questions, most subjects (65$82 \%$ ) did not know that chlamydia caused these complications, such as eye infections or chest infections in babies. There was no significant difference between the sexes in overall chlamydia knowledge scores. However, females were more aware that chlamydia caused infertility $(p=0.04)$, lower abdominal pains $(p<0.01)$, and genital discharge $(p=0.01)$ (table 1).

PATIENT KNOWLEDGE OF INFERTILITY

For five questions relating to fertility the commonest answer (50-63\% of male and female subjects) was "don't know." Most subjects knew that "ovary problems" or "oral contraception" reduced fertility. Females were more aware that herpes infections do not cause infertility $(p=0.02)$. There were no other significant differences between the sexes.

\section{OVERALL PATIENT KNOWLEDGE}

The total knowledge scores were similar in males (median 4.0) and females (median 4.0). Males showed a significantly higher level of
Table 2. Comparison of the actual and preferred sources of health information on gonorrhoea and chlamydia

\begin{tabular}{llll}
\hline $\begin{array}{l}\text { Sources of } \\
\text { information }\end{array}$ & $\begin{array}{l}\text { Actual sources } \\
\text { for gonorrhoea } \\
\text { (\%) }\end{array}$ & $\begin{array}{l}\text { Actual sources } \\
\text { for chlamydia } \\
(\%)\end{array}$ & $\begin{array}{l}\text { Preferred } \\
\text { sources } \\
(\%)\end{array}$ \\
\hline Doctor & $14(9)$ & $25(15)$ & $90(60)$ \\
Nurse & $7(4)$ & $7(4)$ & $28(17)$ \\
TV & $25(15)$ & $11(7)$ & $50(31)$ \\
Radio & $4(2)$ & $2(1)$ & $13(8)$ \\
Leaflets & $40(24)$ & $28(17)$ & $73(45)$ \\
Friend & $27(17)$ & $19(12)$ & $30(18)$ \\
Magazine & $26(16)$ & $21(13)$ & $49(30)$ \\
Newspaper & $10(6)$ & $5(3)$ & $36(22)$ \\
Don't recall & $23(14)$ & $15(9)$ & $-(-)$ \\
Other & $13(8)$ & $7(4)$ & $13(8)$ \\
\hline
\end{tabular}

knowledge about gonorrhoea than about chlamydia $(\mathrm{p}=0.008)$, females did not $(\mathrm{p}=$ $0.53)$.

There was no significant correlation between total or specific knowledge scores and age or Carstairs deprivation scores.

SOURCES OF PATIENT INFORMATION

Equal numbers of participants read leaflets always/often as those who read them rarely/ never. Significantly $(p=0.03)$ more females read leaflets always/often (females $42 / 72$, males $35 / 86$ ) whereas males tended to read them rarely/never (females 30/77, males 51/86).

The median total knowledge score of those 77 participants who read leaflets always/often was 5.0 (IQR 2.0-7.0), significantly higher than the median of 3.0 (IQR 1.5-5.5) for the 81 subjects who rarely or never read these leaflets $(p=0.04)$. Participants' attention to information leaflets was not significantly associated with Carstairs deprivation scores.

The commonest source of information was health information leaflets, followed by friends, women's magazines, and television. Newspapers contributed little. The medical profession was by far the preferred source of health information, followed by health education leaflets, the media (television, women's magazines, and newspapers), nurses, and friends (table 2).

\section{Discussion}

Most participants in this study were relatively young (aged 20-35 years). This is a relatively sexually active age group vulnerable to sexually transmitted diseases. ${ }^{1-6}$

Although most participants knew of the existence of gonorrhoea, they knew little more. Significantly more males had heard of gonorrhoea. Three quarters did not know simple details of the disease. Only $52 \%$ knew that gonorrhoea caused genital discharge, its classic symptom, and were unaware that it may be asymptomatic or that it caused infertility. In the United States, Biro ${ }^{13}$ reported a similar lack of knowledge. These studies highlight the lack of awareness of the features of sexually transmitted diseases.

Barely half the subjects had heard of chlamydia and most knew little about the possible consequences. More females knew it caused infertility, lower abdominal pains, and genital discharge. This may reflect female exposure to health information or personal experience of abdominal pain or infertility. White and Felts ${ }^{11}$ found knowledge to be 
similarly poor in a student population. Interestingly, female student knowledge was significantly better than male. In Ireland, when STD clinic attendees were asked to name any sexually transmitted disease, only $10 \%$ named non-gonococcal urethritis (the most common diagnosis at presentation). ${ }^{12}$

The maximum total knowledge score achievable in this study was 23 . The median score for both sexes was only 4 , most scoring $2-7$. These scores suggest that participants knew little about these conditions. There was no association between knowledge scores and age or socioeconomic status, although there was a significant relation to use of patient information leaflets.

The commonest source of information on gonorrhoea and chlamydia was health information leaflets. Females tended to read leaflets "always/often" whereas males read them "rarely/never." For chlamydia, doctors contributed important information. Patients also indicated that doctors were their preferred information source on sexual health. Doctors may be perceived as authoritative sources by this clinic population. Indeed, this may underlie the mass media's use of "celebrity doctors" in television and women's magazines. Perhaps this could be used to communicate additional health information to the public.

The actual risk of acquiring a sexually transmitted disease depends on many demographic and behavioural factors. ${ }^{48}$ The influence of knowledge of chlamydia on risk behaviour is not well established. However, public knowledge of chlamydia assumes greater importance once a screening programme is initiated. ${ }^{10}$ Without knowledge, individuals may not participate or understand the implications. Educa- tion allows for informed consent. This study has highlighted serious gaps in knowledge of both chlamydia and gonorrhoea that merit attention.

Conflict of interest: None.

We thank the staff at the clinic for their help, and the patients for their participation.

Contributors: PD developed the original concept, drafted the questionnaires, analysed the responses, and drafted the manuscript; $\mathrm{RH}$ contributed to the original concept, questionnaire development, data analysis, and manuscript development $\mathrm{SC}$ contributed to the original concept, literature review, research design, questionnaire development, data analysis, and manuscript drafting and finalisation; BJC contributed to the literature review, questionnaire development, data analysis, and finalisation of the revised manuscript.
finture

1 Mims C, Playfair J, Roitt I, et al. Sexually transmitted diseases. In: Hooper C, ed. Medical microbiology. 1st ed. London: Mosby, 1993:24.1-24.2.

2 Sexually transmitted diseases quarterly report: genital infection with Chlamydia trachomatis in England and Wales. Commun Dis Rep Weekly 1995;5:122-3.

3 Oriel JD, Waugh MA. Sexually transmitted diseases today. $\mathcal{F}$ Roy Soc Med 1988;81:312-4.

4 Weinstock H, Dean D, Bolan G. Chlamydia trachomatis infections. Infect Dis Clin N Am 1994;8:797-819.

Felman YM, Nikitas JA. Nongonococcal urethritis. A clinical review. $\mathcal{F} A M A$ 1981;245:381-6.

6 Cates W, Wasserheit JN. Gonorrhoea, chlamydia, and pelvic inflammatory disease. Curr Opin Infect Dis 1990;3:10-19.

7 Mardh PA. Natural history of genital and allied chlamydial infections. Curr Opin Infect Dis 1992;5:12-7.

8 Aral SO. Changing epidemiology of sexually transmitted diseases. Curr Opin Infect Dis 1990;3:20-3.

9 Department of Health. Chlamydia trachomatis: summary and conclusions of CMO's Expert Advisory Group. London: DoH, conclusion.

10 Boag F, Kelly F. Screening for Chlamydia trachomatis. BMF 1998;316:1474-80

11 White DM, Felts WM. Knowledge of chlamydial infection among university students. Health Educ 1989;20:23-5.

12 Dinsmore WW, Horner T, Maw RD. Knowledge, attitudes and education background of sexually transmitted disease clinic attenders. Irish $\mathcal{F}$ Med Sci 1987;156:9-12.

13 Biro FM, Rosenthal SL, Stanberry LR. Knowledge of gonorrhea in adolescent females with a history of STD. Clin Pediatr 1994;33:601-5.

14 McLoone P, Boddy FA. Deprivation and mortality in Scotland, 1981 and 1991. BMF 1994;309:1465-70.

15 Altman DG. Practical statistics for medical research. London: Chapman and Hall, 1991. 